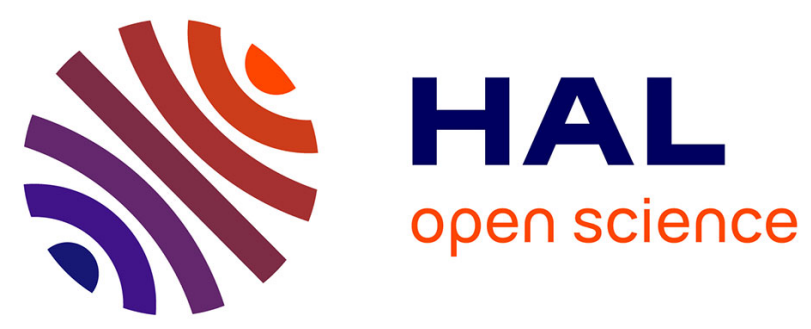

\title{
Polycyclic aromatic hydrocarbon (PAH) formation during acetylene pyrolysis in tubular reactor under low pressure carburizing conditions
}

Tsilla Bensabath, Minh Duy Le, Hubert Monnier, Pierre-Alexandre Glaude

\section{- To cite this version:}

Tsilla Bensabath, Minh Duy Le, Hubert Monnier, Pierre-Alexandre Glaude. Polycyclic aromatic hydrocarbon $(\mathrm{PAH})$ formation during acetylene pyrolysis in tubular reactor under low pressure carburizing conditions. Chemical Engineering Science, 2019, 202, pp.84-94. 10.1016/j.ces.2019.03.030 . hal-02139154

\author{
HAL Id: hal-02139154 \\ https://hal.science/hal-02139154
}

Submitted on 24 May 2019

HAL is a multi-disciplinary open access archive for the deposit and dissemination of scientific research documents, whether they are published or not. The documents may come from teaching and research institutions in France or abroad, or from public or private research centers.
L'archive ouverte pluridisciplinaire HAL, est destinée au dépôt et à la diffusion de documents scientifiques de niveau recherche, publiés ou non, émanant des établissements d'enseignement et de recherche français ou étrangers, des laboratoires publics ou privés. 


\section{Polycyclic Aromatic Hydrocarbon (PAH) Formation during Acetylene Pyrolysis in Tubular Reactor under Low Pressure Carburizing Conditions}

Tsilla Bensabath ${ }^{1,2}$, Minh Duy Le ${ }^{2}$, Hubert Monnier ${ }^{2, *}$ Pierre-Alexandre Glaude ${ }^{1}$

${ }^{1}$ Laboratoire Réactions et Génie des Procédés, CNRS, Université de Lorraine, 1, rue

Grandville, 54001 Nancy, France

${ }^{2}$ Institut National de Recherche et de Sécurité, 1, rue du Morvan, 54519 Vandœuvre-lès-

Nancy, France

*Corresponding author:

Hubert Monnier

INRS, Institut National de Recherche et de Sécurité, 1, rue du Morvan, 54519 Vandœuvre-lèsNancy, France

hubert.monnier@inrs.fr

\section{Highlights}

- Experiments of acetylene pyrolysis at $1173 \mathrm{~K}$ and $8 \mathrm{kPa}$ in a tubular reactor.

- Analysis of products including the 16 EPA-PAHs.

- PAH amounts increase with residence time at low acetylene concentration.

- PAH amounts slightly decrease with residence time for pure acetylene.

- Correct agreement with simulation results, especially for the main products. 


\section{Abstract}

Low-pressure carburizing involves hydrocarbon pyrolysis, which leads to a fast gas-phase formation of polycyclic aromatic hydrocarbons (PAHs), some of which, such as benzo $[a]$ pyrene, are carcinogenic. Workers can be exposed to these PAHs during maintenance and cleaning operations of carburizing furnaces. Experiments of acetylene pyrolysis were carried out in conditions close to low-pressure gas carburizing processes, at $1173 \mathrm{~K}$ and $8 \mathrm{kPa}$, in tubular reactors. At the outlet of the reaction zone, the reactant and the reaction products were analyzed by gas chromatography (TCD, FID and MS). Amongst other products, 16 PAHs classified as priority pollutants by the United States Environmental Protection Agency (US EPA) were observed and quantified. The study of the influence of residence time and of inlet reactant concentration shows that amounts of PAHs increase with residence time at low acetylene concentration but slightly decrease with pure acetylene due to the conversion of PAHs into soot. Results were compared to simulation results obtained with a detailed kinetic model of light hydrocarbon pyrolysis.

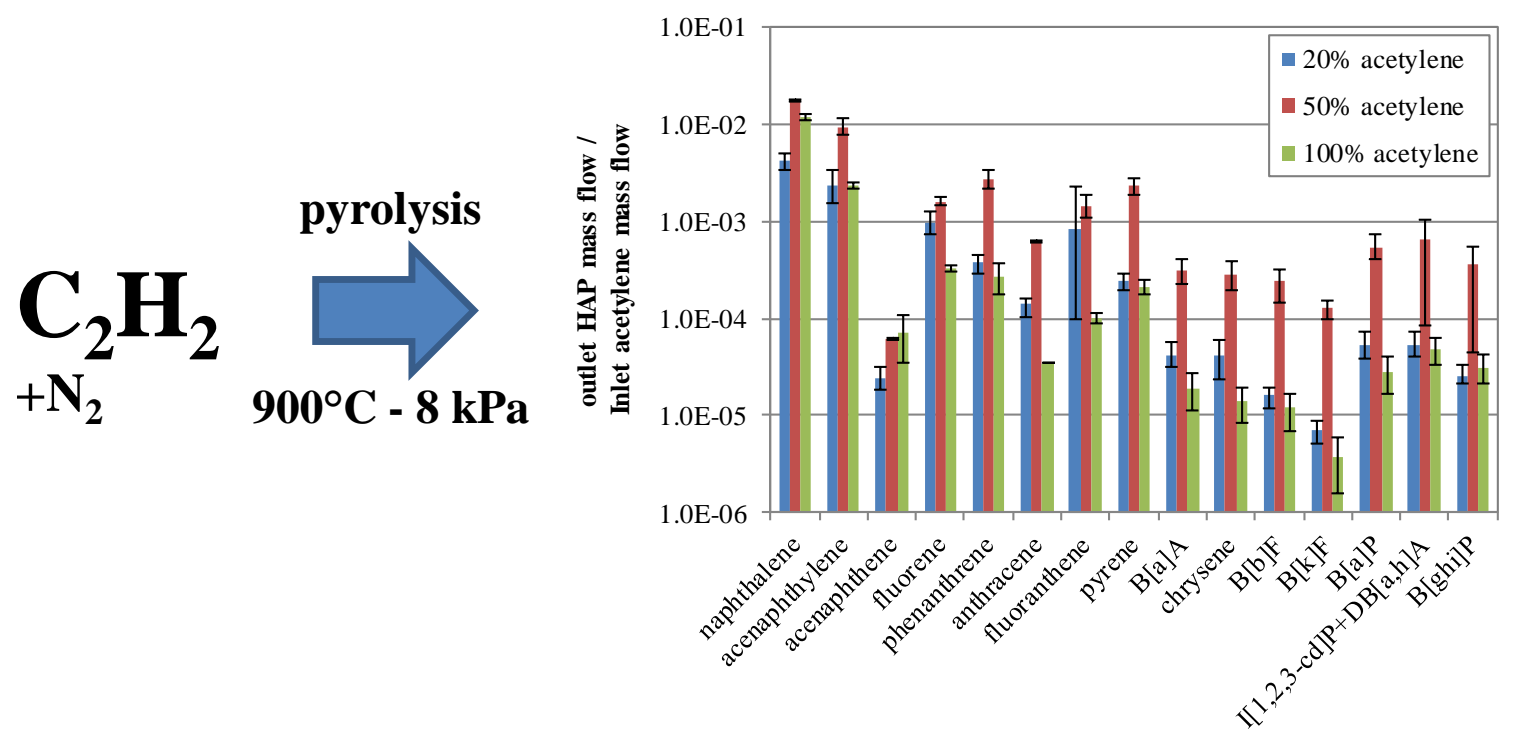

Keywords: Pyrolysis; Acetylene; PAHs; benzo[a]pyrene; low-pressure gas carburizing 


\section{Introduction}

Processes of hydrocarbon pyrolysis and combustion lead to the formation of several species in gas phase, particularly polycyclic aromatic hydrocarbons (PAHs), which are soot precursors (Violi et al., 1999; Richter and Howard, 2000; Kuwana et al., 2006). PAHs are toxic and some of them are carcinogenic (Straif et al., 2005). Sixteen PAHs have been classified as priority pollutants by the Environmental Protection Agency in the United States (EPA-PAHs): naphthalene, acenaphthylene, acenaphthene, fluorene, phenanthrene, anthracene, fluoranthene, pyrene, benzo $[a]$ anthracene $(\mathrm{B}[a] \mathrm{A})$, chrysene, benzo $[b]$ fluoranthene $(\mathrm{B}[b] \mathrm{F})$, benzo $[k]$ fluoranthene $(\mathrm{B}[k] \mathrm{F})$, benzo $[a]$ pyrene $(\mathrm{B}[a] \mathrm{P})$, indeno[1,2,3-cd]pyrene $(\mathrm{I}[1,2,3-c d] \mathrm{P})$, dibenzo $[a, h]$ anthracene $(\mathrm{DB}[a, h] \mathrm{A})$ and benzo $[g h i]$ perylene $(\mathrm{B}[g h i] \mathrm{P})$ (Sánchez et al., 2013a). Their structure is represented in supplementary data $(\mathrm{S} 1)$. In particular, $\mathrm{B}[a] \mathrm{P}$ is carcinogenic to humans according to the International Agency for Research on Cancer (IARC) (IARC, 2017).

One of the processes which lead to PAH formation is low-pressure gas carburizing. Carburizing is used to avoid wear of pieces subject to strong constraints (Yada and Watanabe, 2013). It is a heat treatment process used to harden surface of steel by enriching the metal with carbon atoms. Carbon is obtained from hydrocarbons such as acetylene which react at the surface of steel parts and diffuse into them. However, at the same time, hydrocarbon pyrolysis occurs in the gas phase. PAHs are formed and condense on the cold walls of pipes, valves and vacuum pump downstream of the furnace. Thus, during maintenance and cleaning operations of carburizing furnaces, workers can be exposed to particles or tar containing PAHs by inhalation and skin contact (Champmartin et al., 2017).

Different hydrocarbons are used as a reactant in low-pressure gas carburizing processes. The most common are acetylene, ethylene and propane (Buchholz et al., 2010). This study focuses on acetylene because it is an important intermediate in the growth of PAHs through the 
hydrogen abstraction $\mathrm{C}_{2} \mathrm{H}_{2}$ addition (HACA) mechanism. This mechanism proposed by Frenklach et al. (Frenklach et al., 1984) consists in the elimination of a hydrogen atom from the initial PAH by an $\mathrm{H}$-atom abstraction reaction, followed by the addition of an acetylene molecule on the obtained radical site. Otherwise, acetylene is one of the most efficient hydrocarbons for surface reactions of carburizing and chemical vapor deposition (CVD) (Lacroix et al., 2010). To study the parameters which impact PAH formation, experiments of acetylene pyrolysis were performed in different operating conditions.

The first known pyrolysis of acetylene was performed in 1866 by Berthelot who highlighted the formation of benzene (Berthelot, 1866). Afterward, three kinds of reactors were used to study acetylene pyrolysis: static reactors, flow reactors and shock tubes (Rokstad et al., 2014; Wu et al., 1987). In the present study, flow reactors, generally appropriate for temperatures between 800 and $1500 \mathrm{~K}$, are employed.

In 1929, Pease used a flow reactor to study acetylene pyrolysis in a continuous vessel. He showed that the primary reaction, which involves two acetylene molecules, determines the global reaction rate (Pease, 1929). Stehling et al. studied the formation of solid carbon during acetylene pyrolysis (Stehling et al., 1957). In 1961, they analyzed the pyrolysis products at different temperature from hydrogen to aromatic species containing ten carbon atoms (Stehling et al., 1961). Other studies allowed to highlight the role of vinylacetylene $\left(\mathrm{C}_{4} \mathrm{H}_{4}\right)$ as an intermediate in benzene and solid carbon formation (Hou and Anderson, 1963; Munson and Anderson, 1963). In 2000, Krestinin et al. determined a threshold temperature for soot formation during acetylene pyrolysis at $1200 \mathrm{~K}$ for a partial pressure of acetylene of $13.4 \mathrm{kPa}$ (100 Torr) and a residence time in the reactor of $0.17 \mathrm{~s}$ (Krestinin et al., 2000). Dimitrijevic et al. (2000) studied acetylene pyrolysis at short residence times (between 3 and $50 \mathrm{~ms}$ ) (Dimitrijevic et al., 2000). They found vinylacetylene and benzene to be the primary products with reaction orders of two and three, respectively. Later, other experiments were carried out. 
Twenty-four products were detected, including 15 primary products (Xu and Pacey, 2005). In 2014, Rokstad et al. confirmed that the main products of acetylene pyrolysis are vinylacetylene and benzene at low conversion, but solid carbon and hydrogen at important conversion (Rokstad et al., 2014).

Regarding the 16 EPA-PAHs, few experimental data are available for acetylene pyrolysis. During the period 2010 to 2013, Sánchez et al. quantified them at the outlet of a plug-flow reactor (Sánchez et al., 2012a, 2012b, 2013b, 2010). The reaction was carried out at different temperatures between 873 and $1473 \mathrm{~K}$ and at atmospheric pressure with a diluted reactant, which were sooting conditions. The authors observed that the concentration of PAHs increases with the inlet concentration of acetylene. The study of the impact of temperature showed that the total amount of PAHs reaches a maximum around $1223 \mathrm{~K}$, which is explained by the increase of carbon amount involved in soot formation (Sánchez et al., 2013b). When residence time increases, the amount of light PAHs (from two to four rings) increases while the amount of heavier PAHs reaches a maximum (Sánchez et al., 2012). At low pressure (between 2 and $15 \mathrm{kPa}$ ) and with pure acetylene as a reactant, Norinaga et al. (2006, 2009) measured 13 EPA-PAHs in a plug-flow reactor (Norinaga et al., 2009, 2006). They worked in chemical vapor deposition (CVD) conditions, at temperature between 1073 and $1373 \mathrm{~K}$. They observed that the main products of acetylene pyrolysis are hydrogen, methane, ethylene, vinylacetylene, benzene and naphthalene. In addition to the EPA-PAHs, they also quantified other PAHs including up to seven aromatic rings. They found a global order of reaction of 2.7 with respect to the reactant. This value is higher than other values available in the literature, which are closer to 2 (Hooker, 1958; Ogura, 1977; Silcocks, 1957). Finally, between 2007 and 2012, at the University of Tokyo, PAH formation was studied during acetylene pyrolysis but also during the pyrolysis of aromatic species (benzene, toluene) in a plug-flow reactor (Shukla et al., 2008, 2007; Shukla and Koshi, 2012). The authors highlighted the importance of the 
reactions between aromatic species in the process of PAH growth. They concluded that the formation of heavy PAHs necessarily results from the combination of several reaction pathways.

The aim of this study is to experimentally quantify the set of 16 EPA-PAHs during acetylene pyrolysis at conditions close to low-pressure gas carburizing processes without surface reactions on steel parts. All of these species were not quantified in previous studies in the literature (Norinaga et al., 2006, 2009). Whereas temperature and pressure are constraint by the carburizing process (technical constraints, solid phase state of steel, etc.), the influence of residence time and acetylene concentration were investigated. First investigations were done in a spherical jet-stirred reactor (Matras and Villermaux, 1973; Herbinet et al., 2015), which studied the formation of $\mathrm{H}_{2}$ to $\mathrm{C}_{7}$ during gas carburizing conditions and showed deviation from ideal flow mixing under low pressure (Bensabath et al., 2019). The present study implements a tubular flow reactor closer to ideality, which allows a better kinetic analysis (Norinaga et al., 2006, 2009; Li et al., 2018). Experimental results are compared to simulation results obtained with a detailed kinetic model of hydrocarbon thermal decomposition.

\section{Experimental setup}

\subsection{General description}

Experiments of acetylene pyrolysis are carried out in the experimental setup shown in figure 1. It consists of a gas feeding system, a reaction system, an on-line gas analysis system and a product collection system. Low pressure is reached by means of a rotary vane pump (Edwards E1M18 Atex 3) and controlled thanks to a solenoid control valve (MKS 0248A) and absolute pressure transducers (MKS Baratron ${ }^{\circledR}$ 622B). Gases (acetylene and nitrogen) are taken from gas cylinders (Air Liquide and Air Products ${ }^{\circledR}$ ) and flow rates are adjusted by mass flow controllers (Brooks ${ }^{\circledR}$ SLA 5850S). Two controllers are used for acetylene depending on 
the flow rate: they allow reaching flow rates up to $600 \mathrm{NmL} \cdot \mathrm{min}^{-1}$ and $12000 \mathrm{NmL} \cdot \mathrm{min}^{-1}$, respectively, to study the influence of gas residence time (from 0.5 to $3 \mathrm{~s}$ ).

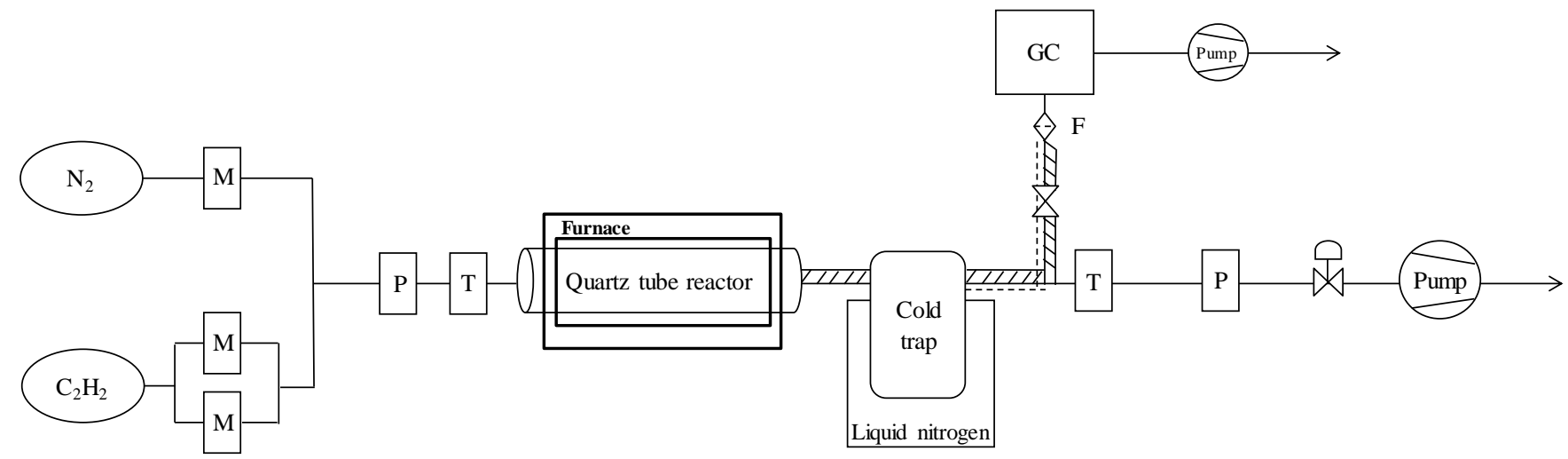

Figure 1: Experimental set-up (----- heating flex; $777 /$ insulation; T: temperature sensor; P: pressure sensor; M: mass flow controller; F: filter)

Reaction takes place in a fused silica tube reactor of $1200 \mathrm{~mm}$ length. Two internal diameters are used: $80 \mathrm{~mm}$ and $16 \mathrm{~mm}$, in order to vary gas residence time. Tubular reactors can be considered as ideal plug-flow reactors in the studied conditions. The Péclet number calculated in the different studied conditions lies between 80 and 220 in the case of the $16 \mathrm{~mm}$ diameter reactor and between 39 and 52 for the $80 \mathrm{~mm}$ diameter reactor. A value above 50 allows to neglect the dispersion and validate the ideal plug flow hypothesis (Hiblot et al., 2016). The reactor is placed horizontally in a tubular three-zone furnace (Carbolite ${ }^{\circledR}$ HZS 12/600) and only $600 \mathrm{~mm}$ length are heated. Radiant panels on each side of the heated area prevent edge effects. Measurements made with thermocouples (type K) along the reactor showed that the relative difference between the actual temperature in the reactor and the setpoint temperature $(1173 \mathrm{~K}$ ) does not exceed $1 \%$ (around $10 \mathrm{~K}$ ) for the reactor of $80 \mathrm{~mm}$ diameter. At the outlet of the reactor, two methods are used to sample and analyze the products of pyrolysis, depending on the molecular weight of the products. 


\subsection{Light product analysis}

Light products (hydrogen and hydrocarbons up to seven carbon atoms) are analyzed on-line by a gas chromatograph (PerkinElmer, Clarus 580 GC adapted by the company Antelia). The GC contains two sampling loops. They fill up simultaneously during the sampling of the gas. This sampling is performed under vacuum by means of a pump located downstream of the GC. Before the analysis, a nitrogen plug-flow compression system allows to bring the pressure to 1.1 bar into the sampling loops. The aim of this operation is to be sure that mole amount in the loops is the same for each analysis, regardless of the operating conditions of the process. Volume and temperature of the loops are constant.

At the beginning of the analysis, the gas is sent in two parallel circuits simultaneously. The first leads to a thermal conductivity detector (TCD) and the second leads to a flame ionization detector (FID). Only hydrogen is quantified by the TCD and molecules quantified by the FID are methane, ethylene, acetylene, 1,3-butadiene, propyne, vinylacetylene, benzene and toluene. Another peak is observed, which may correspond to cyclopentadiene. The peak of allene is mingled with the peak of acetylene. The error induced on the amount of acetylene is negligible because the amount of allene is very low compared to the amount of acetylene (the reactant) in the studied conditions. The accuracy of analyzes is evaluated at $10 \%$ for major species and at $20 \%$ for minor species.

The GC analysis provides the composition in the gas phase entering the GC sampling loops, whereas the heaviest products were condensed and filtered before the inlet of the GC. The error due to this variation of the total molar flow is supposed to be small since gas products represent most of products in molar amounts. 


\subsection{Heavy product analysis}

To analyze heavy products, all species, except the lightest, are condensed on the walls of a cold trap (KGW Isotherm) by liquid nitrogen (Linde group). Analyses of the stream at the outlet of the trap were performed with the on-line gas chromatograph. They showed that the amount of product that is not condensed and goes through the trap is negligible, except for the lightest products, such as hydrogen and methane which are not quantified this way. During experiments with the highest gas flow rate (reactor of $80 \mathrm{~mm}$ diameter), gas analyses by GC at the exit of the trap showed that 3 to $20 \%$ of benzene and 2 to $10 \%$ of toluene (depending on the reactant concentration and the residence time) were not condensed into the trap. It is then possible to neglect the amount of heavier products, especially PAHs, that goes through the trap.

After the sampling, the cold trap is removed from the setup and washed with a known volume of dichloromethane. Samples are analyzed off-line by gas chromatography. Light aromatic species are separated in a column Rxi-624 Sil/MS (0.32 mm diameter, $60 \mathrm{~m}$ length and containing a film of $1.8 \mu \mathrm{m}$ thick) and PAHs are separated in a column Rxi-17 Sil/MS ( $0.25 \mathrm{~mm}$ diameter, $30 \mathrm{~m}$ length and containing a film of $0.25 \mu \mathrm{m}$ thick), which is specifically appropriate for PAHs. The sixteen EPA-PAHs are quantified by a mass spectrometer detector (MS). I[1,2,3-cd] $\mathrm{P}$ and $\mathrm{DB}[a, h] \mathrm{A}$ cannot be separated and are considered together. Other light aromatic species: phenylacetylene, styrene and indene, are quantified by a FID. For these species, the detection threshold is $1 \mu \mathrm{g} \cdot \mathrm{mL}^{-1}$ and, for PAHs, detection thresholds vary from 0.1 to $1.5 \mu \mathrm{g}$ per sample (on a basis of $120 \mathrm{~mL}$ per sample) according to the species. They are gathered in supplementary data (S2).

This analysis method leads to uncertainties because of the different steps between sampling and analysis: potential evaporation of dichloromethane, errors due to successive dilutions before analysis, etc. Losses of products by evaporation can also occur when heating from 
liquid nitrogen temperature up to room temperature. However, it can be assumed that they mainly concern light products. Moreover, experiments of reproducibility were performed. Note that when the on-line gas chromatograph is used, the cold trap is removed from the setup and replaced by a pipe.

\subsection{Operating conditions}

All experiments were carried out at $1173 \mathrm{~K}$ and $8 \mathrm{kPa}$. The feed consisted of acetylene, pure or diluted with nitrogen. Residence time $\tau$ is the ratio between the volume of the reactor and the volumetric flow rate.

Table 1: Operating conditions - All experiments were performed at $1173 \mathrm{~K}$ and $8 \mathrm{kPa}$

\begin{tabular}{|c|c|c|c|c|}
\hline $\begin{array}{c}\text { Reactor } \\
\text { internal } \\
\text { diameter }(\mathbf{m m})\end{array}$ & $\begin{array}{c}\text { Acetylene } \\
\text { fraction in } \\
\text { nitrogen } \\
(\text { molar \%) }\end{array}$ & $\begin{array}{c}\text { Residence } \\
\text { time (s) }\end{array}$ & $\begin{array}{c}\text { Acetylene } \\
\text { flowrate } \\
(\text { NL.min-1) }\end{array}$ & $\begin{array}{c}\text { Acetylene } \\
\text { flowrate at } \\
1173 \mathrm{~K} \text { and } 8 \mathrm{kPa} \\
\left(\text { L.min } \text { - }^{-1}\right)\end{array}$ \\
\hline \multirow{10}{*}{80} & \multirow{5}{*}{20} & 1.5 & 0.44 & 24 \\
\hline & & 2.1 & 0.32 & 17 \\
\hline & & 2.4 & 0.28 & 15 \\
\hline & & 2.7 & 0.25 & 13 \\
\hline & & 3 & 0.22 & 12 \\
\hline & \multirow{5}{*}{50} & 1.5 & 1.11 & 60 \\
\hline & & 2.1 & 0.79 & 43 \\
\hline & & 2.4 & 0.69 & 38 \\
\hline & & 2.7 & 0.61 & 34 \\
\hline & & 3 & 0.55 & 30 \\
\hline \multirow{4}{*}{16} & \multirow{4}{*}{100} & 0.5 & 0.27 & 14 \\
\hline & & 1 & 0.13 & 7.2 \\
\hline & & 1.5 & 0.088 & 4.8 \\
\hline & & 1.75 & 0.076 & 4.1 \\
\hline
\end{tabular}


Three molar concentrations of acetylene were tested: $20 \%, 50 \%$ and $100 \%$. Dilution allowed investigating different concentrations under the same total pressure. Furthermore, diluted reacting mixture permitted to reach longer residence time with limited soot formation. Residence time was set between 0.5 and $3 \mathrm{~s}$. In the case of diluted mixtures in the $80 \mathrm{~mm}$ diameter pipe, the minimum residence time was conditioned by the range of mass flow controllers to $1.5 \mathrm{~s}$. Shorter residence times have been studied in the case of pure acetylene, but long residence times leading to significant conversions have been omitted to avoid massive soot formation and reactor fouling. Solid deposits were observed on reactor wall: pyrolytic carbon in the hot part of the reactor and soot at the exit of the reactor where temperature drops. After each experiment, reactors were cleaned by oxidation of carbon at $1173 \mathrm{~K}$ with an air inlet into the reactor. This cleaning avoids heterogeneous effects on next experiment. Table 1 summarizes the tested operating conditions. Each experiment was performed two to four times to test the reproducibility. Thereafter, for the presentation of the results, an average is used for each case and the range between the lowest and the highest values is represented by an error bar.

\section{Modeling}

The model used for simulations were presented in a previous study (Bensabath et al., 2016). It is a detailed kinetic model which describes the reactions of light hydrocarbon pyrolysis and the formation and growth of PAHs up to seven aromatic rings (Frenklach et al., 1984; Rota et al., 1994; Dai et al., 1999; Norinaga and Deutschmann, 2007; Norinaga et al., 2009). It is mainly focused on the formation of the sixteen EPA-PAHs at low pressure. It contains 363 species and 1255 reactions. The model was previously validated with experimental data from the literature, especially with data of Norinaga and Deutschmann (Norinaga and 
Deutschmann, 2007) for acetylene and ethylene pyrolysis at low pressure. Flux and sensitivity analyses were achieved to better understand reaction pathways of benzene and PAH formation (Bensabath et al., 2016). Simulations were performed using the PSR (Perfectly Stirred Reactor model) module in the Chemkin software suite. Tubular reactors, considered as plug-flow reactors, were modeled as a succession of fifty continuous small well-stirred reactors, which ensured grid independent results.

\section{Results and discussion}

\subsection{Generalities}

All experimental results compared to simulation results are available in supplementary data (Figures in S3 and mole fractions in S4). Some results are presented in molar fractions (light species, analyzed on-line) and others are presented in mass fractions (heavy species, analyzed off-line). The units are different because of the different kinds of analyzers. The total mole flow varies between the inlet and the outlet of the reactor due to reactions and the mole flow at the outlet of the reactor is unknown. So, it is not possible to make conversions in order to have all the results expressed in the same way. For the same reason, acetylene conversion cannot be precisely calculated and results for acetylene are expressed in mole fractions.

Experiments at $20 \%$ and $50 \%$ acetylene at the inlet of the reactor were carried out with the tube reactor of $80 \mathrm{~mm}$ diameter. The shortest residence time of $1.5 \mathrm{~s}$ led to a somewhat important conversion of acetylene in the present conditions, so results at low conversion are not available. With pure acetylene, the reactor of $16 \mathrm{~mm}$ diameter was used and experiments at lower residence times were performed. Nevertheless, results are more heterogeneous because of the important conversion of acetylene which leads to the formation of soot and solid deposits and generates experimental complications. It is therefore hard to distinguish clear trends with this small reactor, especially for PAHs. 
Regardless of the operating conditions, some general results are highlighted. They can be observed in figures 2 to 7, detailed further, and in S3. Amongst the light species, acetylene is not completely converted and remains always predominant. Then, hydrogen is produced in large amount because $\mathrm{PAH}$ formation leads to an increase of the $\mathrm{C} / \mathrm{H}$ ratio in heavy products and to $\mathrm{H}_{2}$ formation. Methane, ethylene, vinylacetylene and benzene are also formed in important amounts but there are less propyne and 1,3-butadiene. Regarding aromatic rings with linear branches, phenylacetylene is the main product. That can be explained by the large amount of acetylene and the fact that phenylacetylene is produced through the HACA mechanism from benzene (Bensabath et al., 2016). Amongst PAHs, naphthalene and acenaphthylene are predominantly formed. The relative importance of heavier PAHs depends on the operating conditions. However, phenanthrene and pyrene are always formed in big amount; $\mathrm{B}[b] \mathrm{F}$ and $\mathrm{B}[k] \mathrm{F}$ are always very little formed. 


\subsection{Reactant and light products}

Figure 2 presents the evolution of the normalized acetylene mole fraction at the outlet of the reactor with respect to acetylene mole fraction at the inlet as a function of the residence time. Results for the three inlet concentrations are represented. Acetylene is the reactant, so its fraction decreases when residence time increases, except for $20 \%$ acetylene at the inlet. In this last case, the profile suggests that the results are distorted by errors in the experiments, especially for the point at $1.5 \mathrm{~s}$ of residence time.

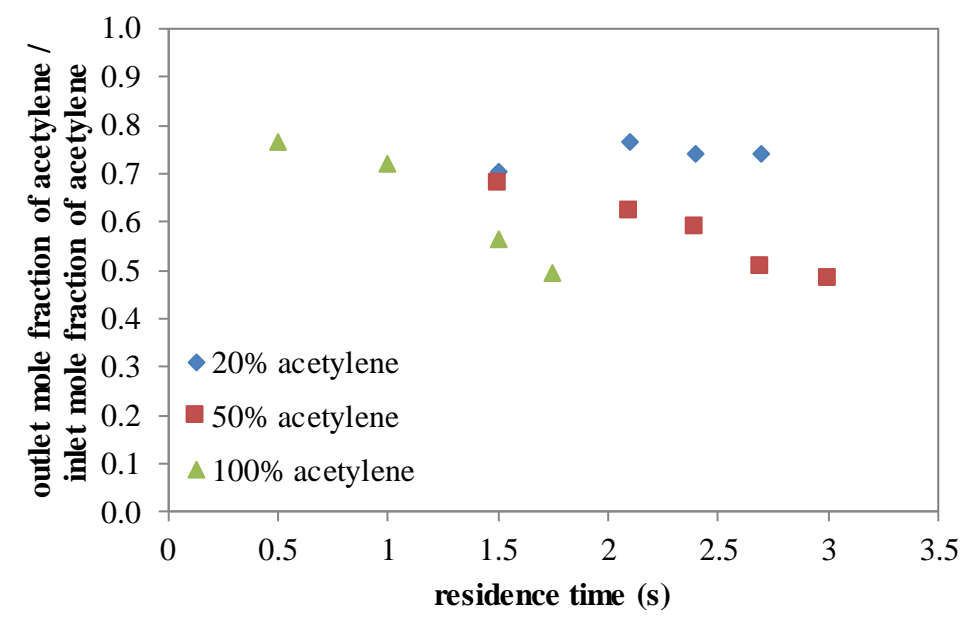

Figure 2: Comparison of acetylene mole fractions at the outlet of the reactor divided by the inlet concentration as a function of the residence time between different inlet concentrations

The only residence time for which experiments are available for $20 \%, 50 \%$ and $100 \%$ acetylene is $1.5 \mathrm{~s}$. At that time, it appears that the higher the acetylene concentration, the more acetylene is consumed. This trend is confirmed because the rate of decrease of the mole fraction as a function of the residence time increases with the concentration (considering the uncertainty of the profile at $20 \%$ ).

Experimental results and simulations obtained for light species with pure acetylene are presented in Figure 3. Graphs represent the evolution of mole fractions plotted as a function of the residence time into the reactor for acetylene, hydrogen, methane, ethylene, propyne, 
vinylacetylene, 1,3-butadiene, benzene and toluene. Such as acetylene mole fraction, vinylacetylene, propyne and toluene fractions decrease when residence time increases.
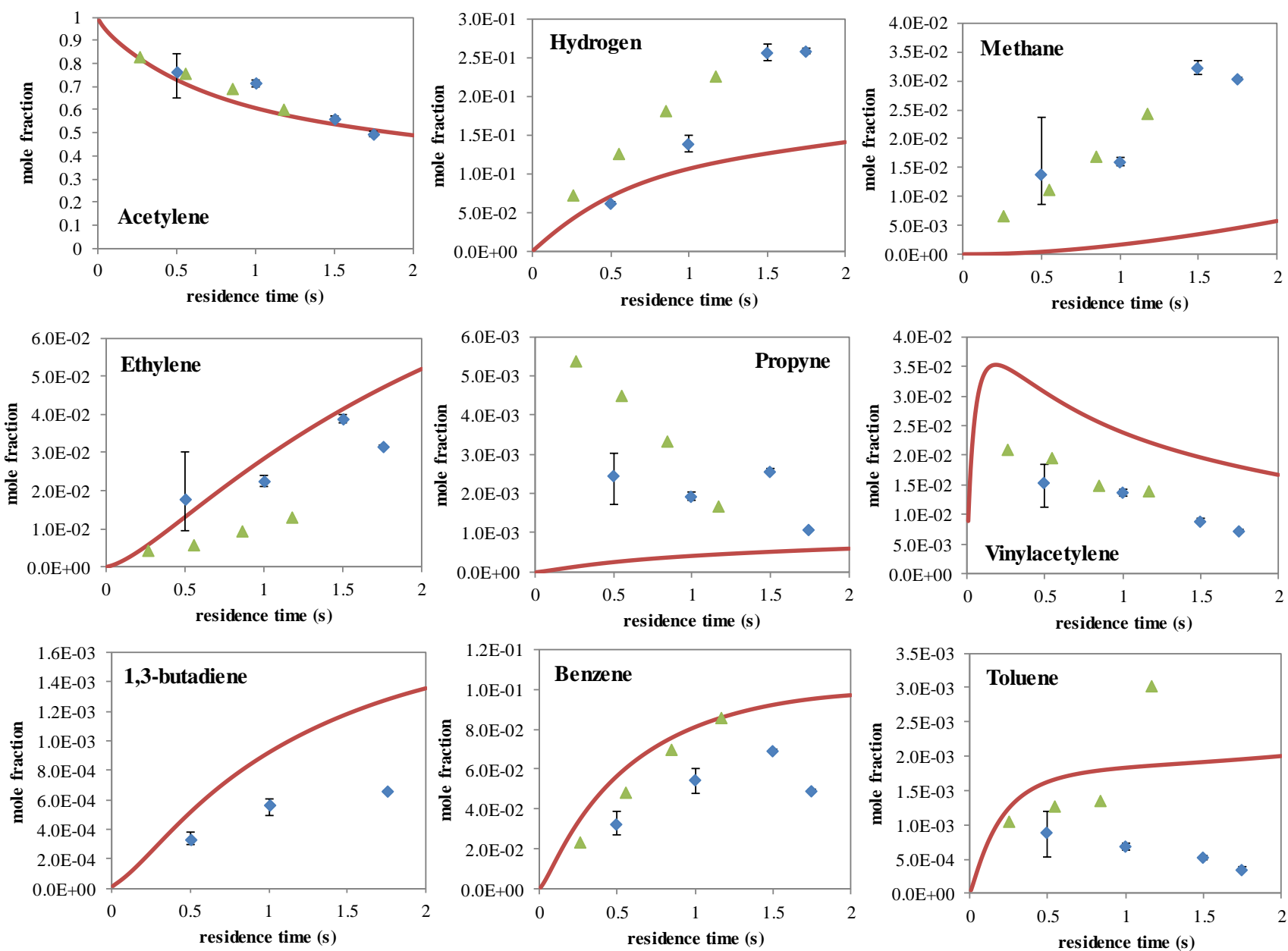

Figure 3: Mole fraction profiles of light species with pure acetylene $(\diamond$ experiments;

simulation) - Comparison with experimental data of Norinaga and Deutschmann with an inlet composition of $98 \%$ acetylene, $0.2 \%$ methane and $1.8 \%$ acetone (Norinaga and Deutschmann,

$$
\text { 2007) ( }(\Delta)
$$

On the contrary, hydrogen, methane, ethylene and benzene fractions increase. 1,3-butadiene was not detected with $20 \%$ acetylene at the inlet. With $50 \%$ and $100 \%$ acetylene, its fraction increases when residence time decreases. The model simulates very well the reactant conversion. The profiles of the main products, i.e. ethylene, and benzene, are in good agreement with experimental results, as well as vinylacetylene and 1,3-butadiene. Hydrogen is underestimated for longer residence times. This can be due to the formation of soot and 
solid pyrocarbon during experiments leading to hydrogen released in gas phase. Soot formation is indeed not included in the model. This analysis is supported by the increasing gap between experimental and simulation results with residence time and, therefore, with the progress of pyrolysis reactions. Methane is underestimated by a factor 5. The formation of methane during the pyrolysis of an unsaturated species such as acetylene is difficult to predict precisely because of the low $\mathrm{C} / \mathrm{H}$ ratio of the reactant and some reaction channels may be missing. Among minor light products, propyne is also underestimated by the model and toluene is overestimated. Evolution as a function of the residence time for light species is similar regardless of the inlet acetylene concentration (S3).

\subsection{Comparison with the literature}

Experimental data obtained in conditions close to experiments with the reactor of $16 \mathrm{~mm}$ diameter were carried out by Norinaga and Deutschmann (Norinaga and Deutschmann, 2007). Pyrolysis of acetylene was realized in a tube reactor at $1173 \mathrm{~K}$ and $8 \mathrm{kPa}$. The inlet feed was composed of $98 \%$ acetylene, $0.2 \%$ methane and $1.8 \%$ acetone. Figure 3 presents results of Norinaga and Deutschmann compared to results of this work for light species available in both cases: acetylene, hydrogen, methane, ethylene, propyne, vinylacetylene, benzene and toluene. Acetone came in Norinaga's work from acetylene bottle, in which it is used to stabilize the hydrocarbon. GC analyses of fresh acetylene at the outlet of the bottle did not show any acetone in our work. So, simulations did not consider this impurity.

The orders of magnitude of mole fractions are identical for both sets of points: $10^{-1}$ for hydrogen; $10^{-2}$ for methane, ethylene, vinylacetylene and benzene; $10^{-3}$ for propyne and toluene. A good agreement is observed between the results of the two studies. It is particularly true for acetylene and methane, but also for vinylacetylene for which the decrease with residence time, following an important production at low residence time, appears in both 
cases. The growing trend of mole fractions with residence time for hydrogen, methane, ethylene and benzene of Norinaga and Deutschmann experiments is also observed in the current study. Nevertheless, it appears that these species reach a plateau (for hydrogen) or begin to decrease (for methane, ethylene and benzene) at large residence times (experiment at $\tau=1.75 \mathrm{~s})$. Regarding profile shapes, the only differences between the two sets of experiments are observed for species formed in small amount: propyne and toluene. For toluene, the profile shape appears to be decreasing for experiments of this study and increasing for experiments of Norinaga and Deutschmann. However, only the last experiment of Norinaga and Deutschmann (at residence time $1.2 \mathrm{~s}$ ) clearly shows a growing mole fraction. The three other points seem to be moving toward a stabilization.

\subsection{PAHs}

Figure 4 presents a comparison of the results obtained for the 16 EPA-PAHs at the three inlet acetylene concentrations, for a residence time of $1.5 \mathrm{~s}$. PAH mass flows at the outlet of the reactor are normalized with respect to acetylene mass flow at the inlet of the reactor. This representation makes possible not to take into account the inert and thus to make comparable the amount of PAHs obtained at each acetylene concentration.

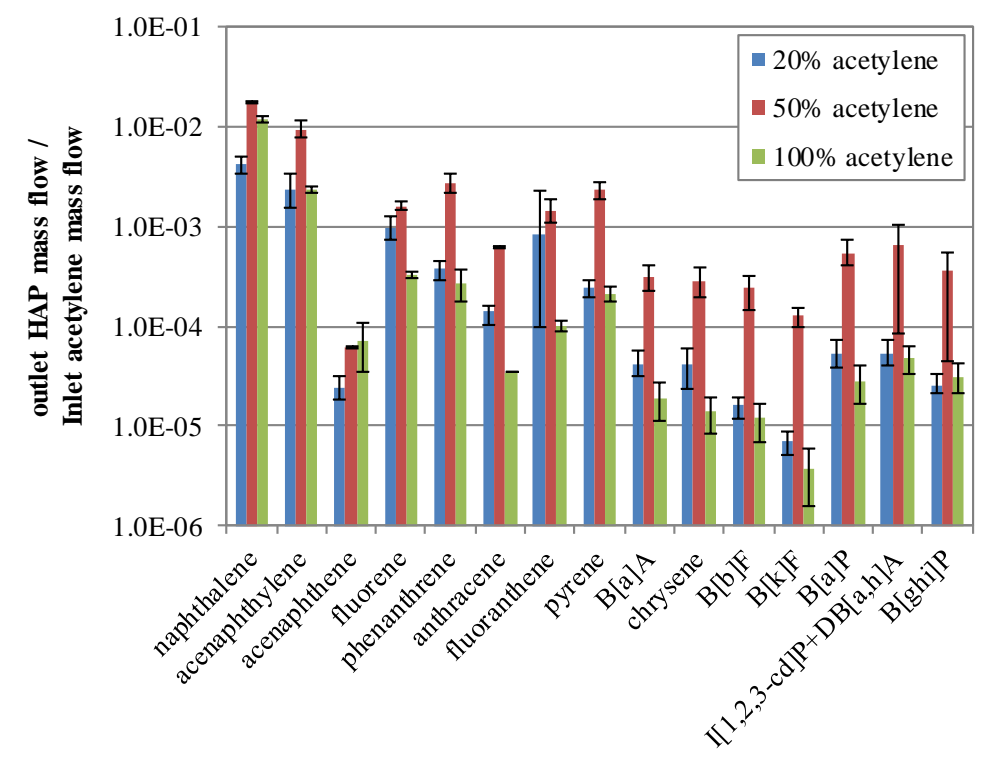


Figure 4: Comparison of PAH mass fractions between different inlet concentrations at $1.5 \mathrm{~s}$ of residence time

Figure 4 allows comparing the relative amounts of each PAH. By classifying PAHs by decreasing abundance, the order obtained is independent of the initial acetylene concentration, so reaction pathways of PAH formation do not depend on acetylene concentration. The following orders of magnitude are for pure acetylene because fractions represented in figure 4 for this case correspond to mass fractions. The most abundant PAH is always naphthalene (fraction around $10^{-2}$ at $100 \%$ acetylene). The second is acenaphthylene (fraction around $10^{-3}$ ). Other important PAHs are fluorene, phenanthrene, fluoranthene and pyrene (fractions around $10^{-4}$ ). They are the lightest PAHs, except for acenaphthene and anthracene (fractions around $10^{-5}$ ). Heavier PAHs are less produced (fractions around $10^{-6}-10^{-5}$ ) but, amongst them, $\mathrm{B}[a] \mathrm{P}$ is still present in significant amounts, more than $\mathrm{B}[a] \mathrm{A}$, chrysene, $\mathrm{B}[b] \mathrm{F}$ and $\mathrm{B}[k] \mathrm{F}$ (lighter). Regarding the comparison between the different inlet acetylene concentrations at $1.5 \mathrm{~s}$ of residence time, for all PAHs except acenaphthene, fractions present an increase between $20 \%$ and 50\% reactant, together with the increase of acetylene conversion (Figure 2). A decrease is observed between $50 \%$ and $100 \%$, although the conversion is yet more important at $100 \%$ than at $50 \%$, but these results are obtained in a different reactor. This evolution can be explained by the conversion of PAHs into heavier species and soot, which were not quantified. As more soot is produced at important acetylene conversion, it is also possible that the decrease of PAH amount during neat acetylene pyrolysis is due to losses of PAHs by adsorption on soot particles. Experiments with pure acetylene were performed in the $16 \mathrm{~mm}$ diameter tube instead of the $80 \mathrm{~mm}$ diameter. The strong increase of the ratio between wall surface and reactor volume favors the loss of heavy products at the wall and in the cooler section of the reactor before the trap used for the analyses. 
Figure 5 presents the evolution of mass fractions of the 16 EPA-PAHs plotted as a function of the residence time at $50 \%$ acetylene at the inlet, compared with simulation data. To compare, figures 6 and 7 present the profiles obtained for six PAHs of different sizes: naphthalene (two rings), phenanthrene (three rings), fluoranthene, pyrene (four rings), $\mathrm{B}[a] \mathrm{P}$ (five rings) and $\mathrm{B}[$ ghi $] \mathrm{P}$ (six rings), at $20 \%$ and $100 \%$ acetylene at the inlet, respectively. Profiles for other PAHs are available in S3, while numerical data are gathered in S4 in the Supplemental Material. Unlike for light species, differences in PAH profiles are observed depending on reactant concentration. The evolution of mass fractions seems to increase with residence time when acetylene concentration is $20 \%$ and $50 \%$, with a slight decrease at $50 \%$ for important residence times (experiment at 3 s). With $100 \%$ acetylene, PAHs seem to have reached a plateau, or even to show a certain decrease (not considering the point at $1 \mathrm{~s}$ of residence time). These trends are not clear because of quite significant experimental gap observed in a same condition.

Regarding the comparison between experiments and modeling, at 20\% acetylene at the inlet, all PAHs are underestimated by the model. Nevertheless, results are close to experimental points for naphthalene, acenaphthylene and phenanthrene. Orders of magnitude for PAHs are better reproduced by the model at $50 \%$ and $100 \%$ acetylene, even if many PAHs, especially the heaviest, are still underestimated. At $100 \%$ acetylene, the model does not reproduce slightly decreasing trends of PAHs with residence time. So, most of PAHs are underestimated at low residence time (under $1 \mathrm{~s}$ ) and overestimated at important residence time (over $1 \mathrm{~s}$ ). Exceptions are acenaphthylene and phenanthrene, always overestimated, and acenaphthene, $\mathrm{B}[g h i] \mathrm{P}$ and the sum of $\mathrm{I}[1,2,3-c d] \mathrm{P}$ and $\mathrm{DB}[a, h] \mathrm{A}$, always underestimated (S3). The difference observed for trends for pure acetylene pyrolysis between experiments and modeling is certainly due to a higher conversion in these conditions. 

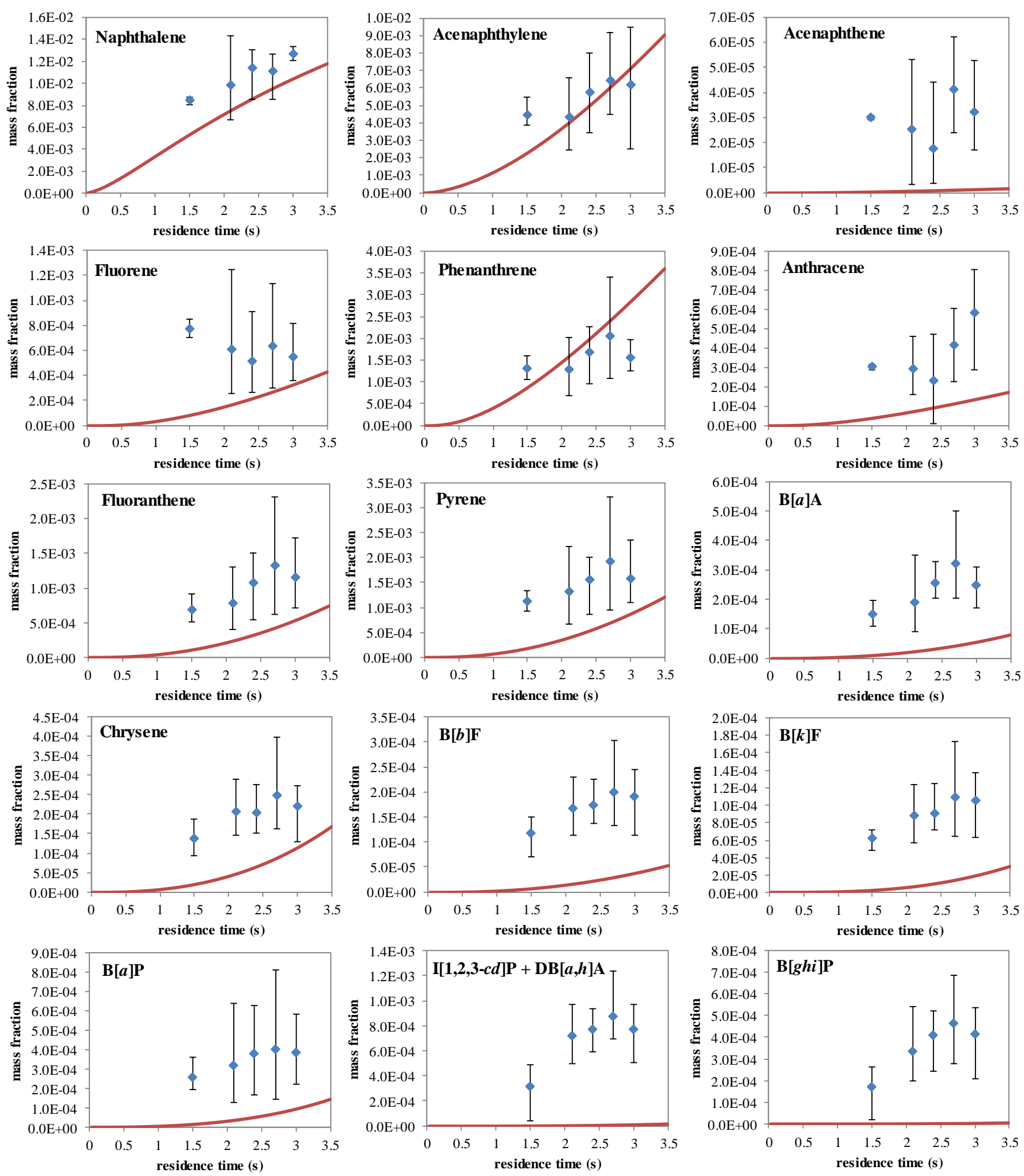

Figure 5: Mass fraction profiles of PAHs at $50 \mathrm{~mol} \%$ acetylene at the inlet ( $\diamond$ experiments; - simulation)

A part of PAHs may be consumed to form heavier species, such as soot, which are not considered in the model (Yan et al., 2012). 

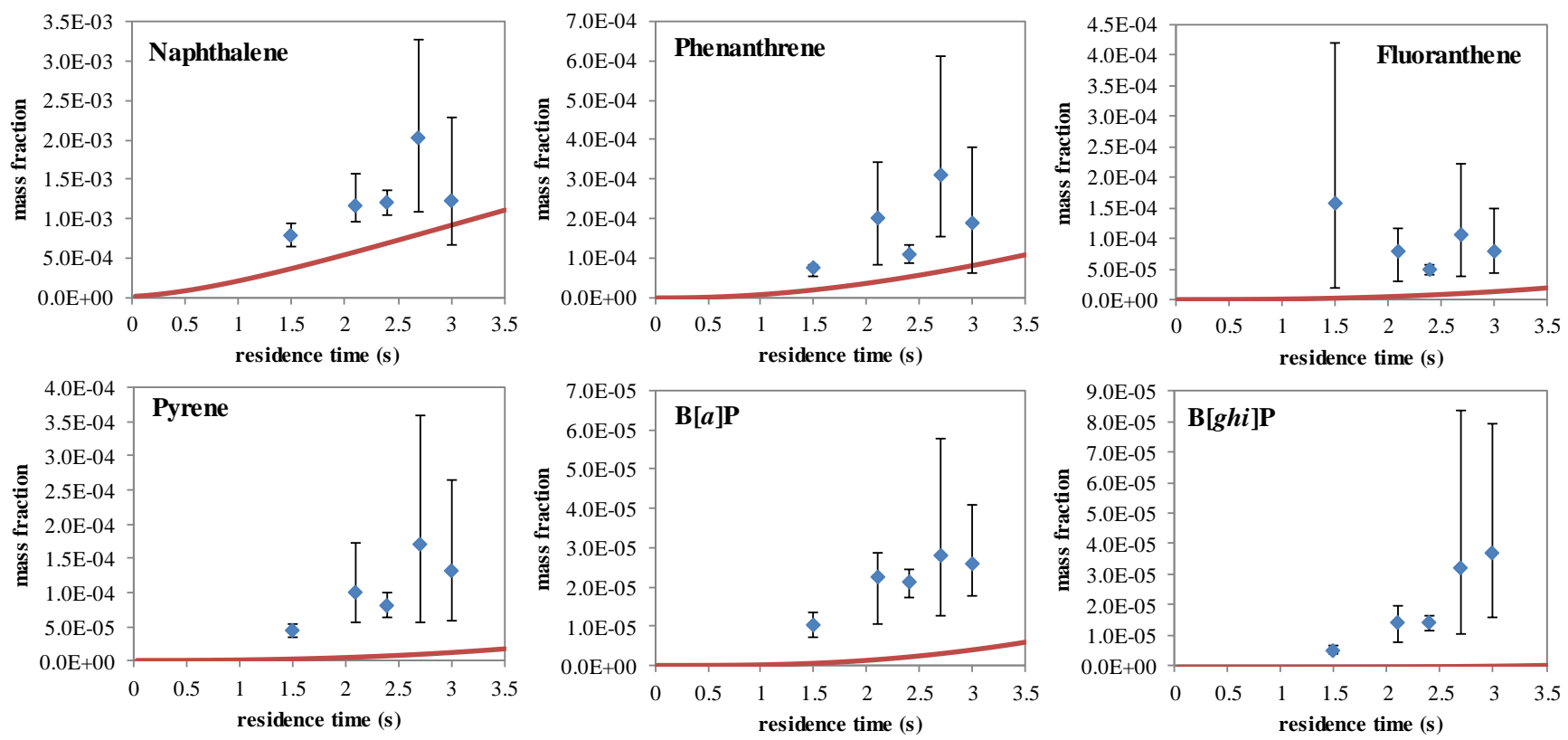

Figure 6: Mass fraction profiles of PAHs at $20 \mathrm{~mol} \%$ acetylene at the inlet ( $\diamond$ experiments; - simulation)
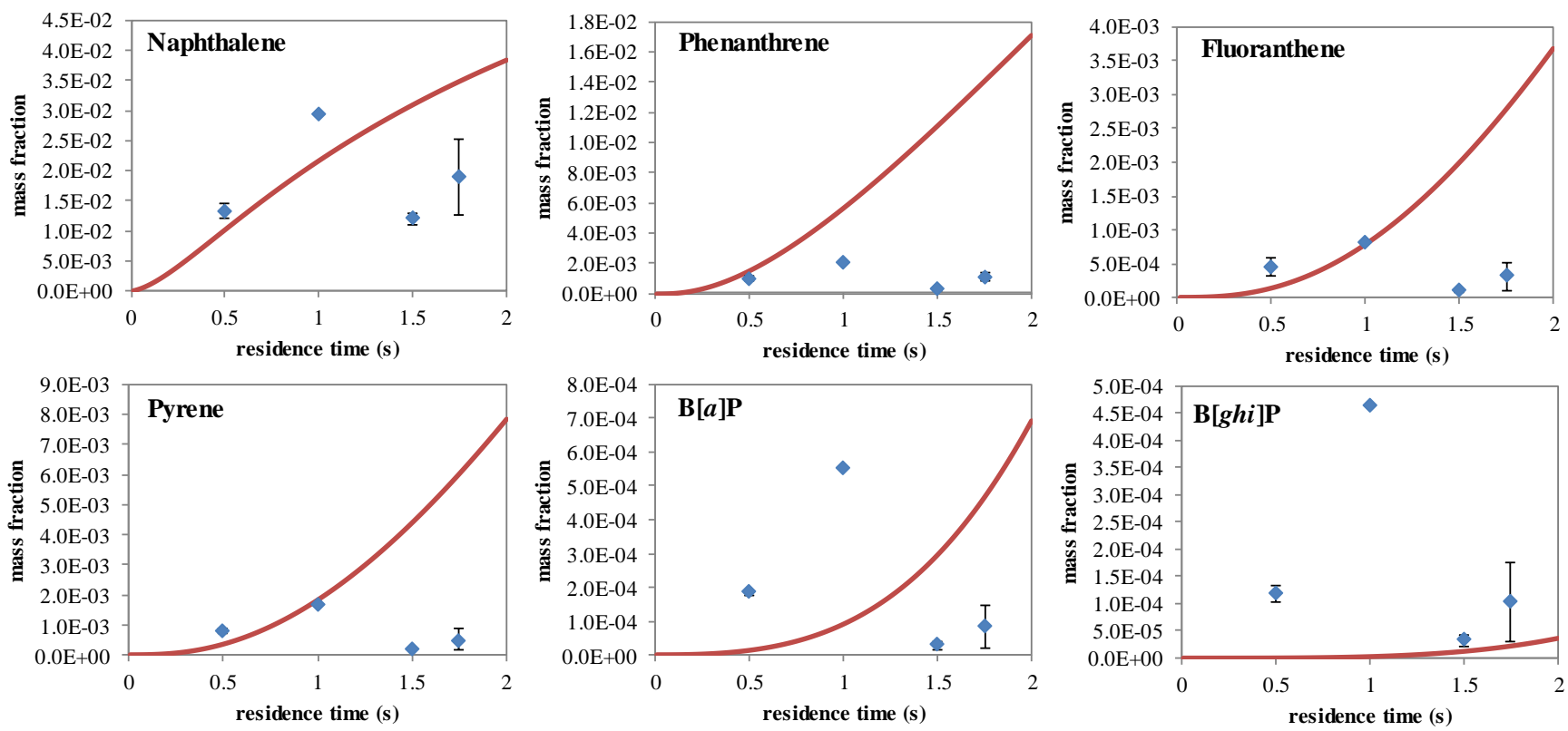

Figure 7: Mass fraction profiles of PAHs at 100\% acetylene at the inlet ( $\diamond$ experiments;

simulation)

Moreover, the amount of adsorbed PAHs on soot increases with the amount of soot. Underestimation of heavier PAHs (B $[g h i] \mathrm{P}, \mathrm{I}[1,2,3-c d] \mathrm{P}, \mathrm{DB}[a, h] \mathrm{A})$ can eventually be due to some missing reaction pathways in the model. 
These results highlight the influence of residence time and inlet concentration on PAH formation but also on soot formation. To limit the formation of these toxic compounds, processes of low-pressure gas carburizing alternate a feed of hydrocarbon (acetylene) and a feed of inert. These cycles allow to stop pyrolysis reactions in gas phase during the time of carbon diffusion into steel parts. Results proposed here could lead to an optimization of the duration of cycles.

\subsection{Reaction pathways of PAH growth}

To better understand the link between the 16 EPA-PAHs, flux analyses were carried out with the kinetic model at $1173 \mathrm{~K}$ and $8 \mathrm{kPa}$. Figure 8 summarizes the grow-out of PAHs from first rings. Only the very major pathways are represented and pathways through intermediate radicals are not detailed. The figure allows highlighting the predominance of two PAH growth mechanisms: the HACA mechanism (arrows in broad dots) and reactions between aromatic species (arrows in small dots). It is also possible to notice the role of naphthalene and phenanthrene, from which most of other PAHs are formed. This information is useful because these two species are formed in important amount (Figure 4) and their formation is well represented by the model, at least at $20 \%$ and $50 \%$ acetylene at the inlet (Figures 5 and 6). To find optimal conditions for a low formation of heavy PAHs, it may be interesting and easier to focus on decreasing the formation of these two species. 


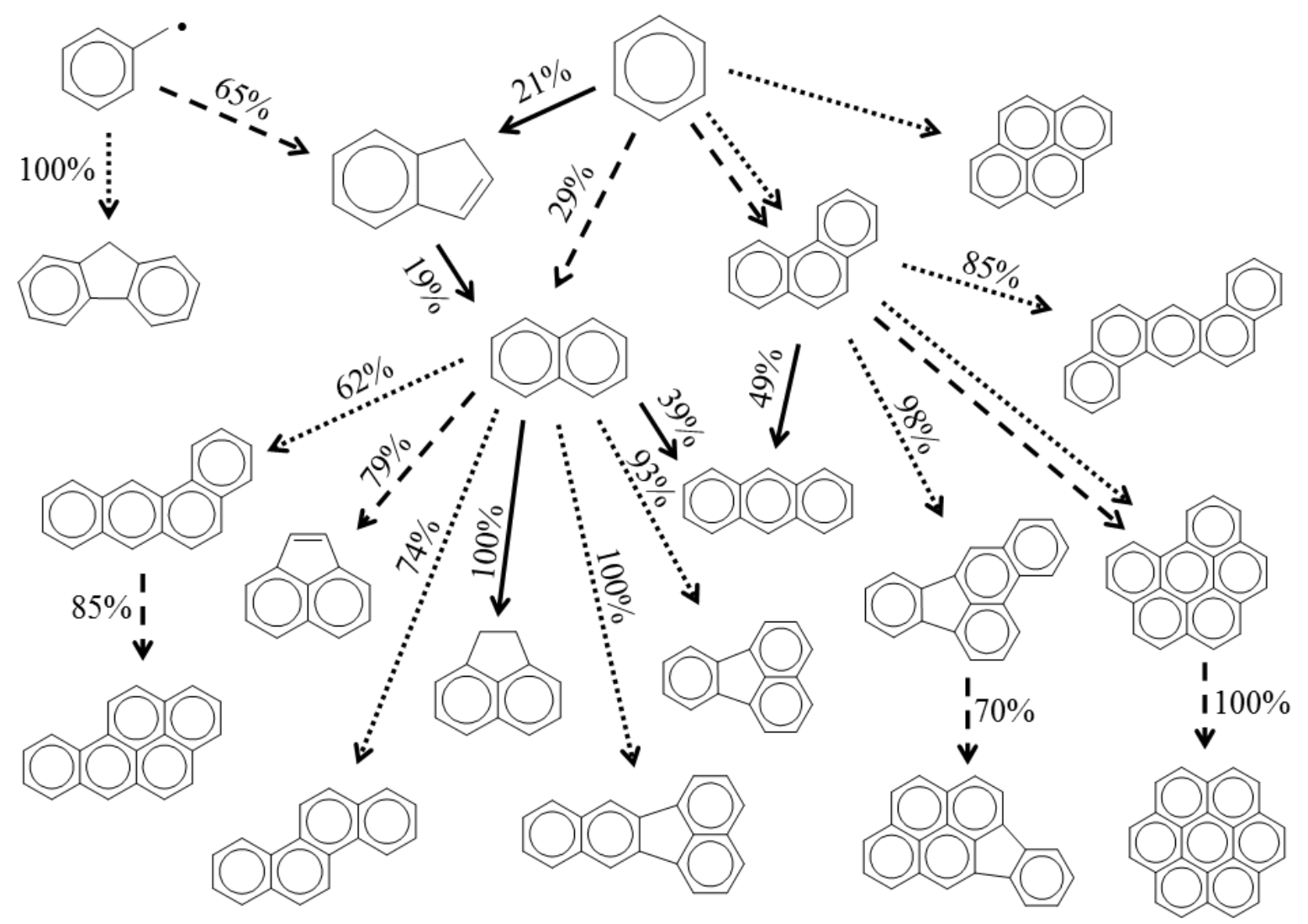

Figure 8: PAH growth during acetylene pyrolysis $(--\rightarrow$ HACA mechanism;...$\cdots \cdots \rightarrow$ reactions between aromatic species) - Percentages are related to the weight of the reaction in the formation of products (obtained at $1173 \mathrm{~K}, 8 \mathrm{kPa}$ and $1 \mathrm{~s}$ of residence time)

\section{Conclusion}

A new experimental setup was developed to study the pyrolysis of acetylene in low-pressure gas carburizing conditions. The aim is to understand the operational parameters which impact the formation of toxic PAHs. Emphasis is on the sixteen EPA-PAHs. Reaction takes place in tubular reactors and products are analyzed by gas chromatography with different detectors. Several residence times and reactant concentrations were studied at $1173 \mathrm{~K}$ and $8 \mathrm{kPa}$.

Comparison of analyzed light species with data from the literature allowed to validate the experimental protocol. However, at our knowledge, these are the first experimental results 
reported for the sixteen EPA-PAHs in carburizing conditions, i.e. for low pressure acetylene pyrolysis.

Results show that light PAHs are the most formed in the studied conditions. Amounts of PAHs seem to increase with the residence time at low acetylene concentration but to slightly decrease with pure acetylene. This decrease can be explained by the conversion of PAHs into heavier products, notably into soot. These results highlight the link between acetylene conversion and PAH concentration. So, it seems preferable to work at low conversion in the gas phase. A high conversion allows to decrease PAH concentration, but favors heavier PAH and soot, which toxicity need to be assessed. An optimization of the operating conditions must also consider constraints required for a good carburizing of steel parts.

If trends and orders of magnitude obtained are reliable, significant uncertainties on the results remain, especially for heavy species. They could be reduced by improving the evaluation of losses during the sampling and by quantifying the formation of soot.

Experimental results are in agreement with simulation data for reactant and main primary products of acetylene pyrolysis, except methane, which is underestimated. Regarding PAHs, orders of magnitude are globally predicted, except for the heaviest PAHs, which are underestimated by the model. Differences observed in some PAH profiles and for hydrogen and methane can be due to heterogeneous reactions, which are not considered by the model.

For the future, further experiments are planned with an iron part into the reactor to get closer to the gas carburizing process conditions and to show the influence of surface reactions on the generation of PAHs. This study can also allow optimizing the feeding conditions in carburizing processes.

\section{Supplementary data}

Supplementary data associated with this article can be found in the online version. 


\section{References}

1 Bensabath, T., Monnier, H., Glaude, P.-A., 2019. Acetylene pyrolysis in a jet-stirred-reactor

2 for low pressure gas carburizing process - Experiments, kinetic modeling and mixing 3 intensity investigations by CFD simulation. Chem. Eng. Sci. 195, 810-819. 4 https://doi.org/10.1016/j.ces.2018.10.028

5 Bensabath, T., Monnier, H., Glaude, P.-A., 2016. Detailed kinetic modeling of the formation of toxic polycyclic aromatic hydrocarbons (PAHs) coming from pyrolysis in low-pressure gas carburizing conditions. J. Anal. Appl. Pyrolysis 122, 342-354. https://doi.org/10.1016/j.jaap.2016.09.007

Berthelot, M., 1866. Théorie des corps pyrogénés. Ann. Chim. Phys. 9, 469.

Buchholz, D., Khan, R.U., Bajohr, S., Reimert, R., 2010. Computational Fluid Dynamics Modeling of Acetylene Pyrolysis for Vacuum Carburizing of Steel. Ind. Eng. Chem. Res. 49, 1130-1137. https://doi.org/10.1021/ie900996h

Champmartin, C., Jeandel, F., Monnier, H., 2017. Maintenance of Low-Pressure Carburising Furnaces: A Source of PAH Exposure. Ann. Work Expo. Health. https://doi.org/10.1093/annweh/wxw024

Dai, B., Fan, Y.S., Yang, J.Y., Xiao, J.D., 1999. Effect of radicals recombination on acetylene yield in process of coal pyrolysis by hydrogen plasma. Chem. Eng. Sci. 54, 957-959.

Dimitrijevic, S.T., Paterson, S., Pacey, P.D., 2000. Pyrolysis of acetylene during viscous flow at low conversions; influence of acetone. J. Anal. Appl. Pyrolysis 53, 107-122. https://doi.org/10.1016/S0165-2370(99)00060-1

Frenklach, M., Clary, D.W., Gardiner Jr., W.C., Stein, S.E., 1984. Detailed kinetic modeling of soot formation in shock-tube pyrolysis of acetylene. Symp. Int. Combust., Symposium (International) on Combustion 20, 887-901. https://doi.org/10.1016/S0082-0784(85)80578-6 Herbinet, O., Husson, B., Le Gall, H., Battin-Leclerc, F., 2015. Comparison study of the gasphase oxidation of alkylbenzenes and alkylcyclohexanes. Chem. Eng. Sci. 131, 49-62. https://doi.org/10.1016/j.ces.2015.03.026

Hiblot, H., Ziegler-Devin, I., Fournet, R., Glaude, P.A., 2016. Steam reforming of methane in a synthesis gas from biomass gasification. Int. J. Hydrog. Energy 41, 18329-18338. https://doi.org/10.1016/j.ijhydene.2016.07.226 
Hooker, W.J., 1958. Shock tube studies of acetylene decomposition. Symp. Int. Combust. 7, 949-952. https://doi.org/10.1016/S0082-0784(58)80142-3

Hou, K.C., Anderson, R.C., 1963. Comparative Studies of Pyrolysis of Acetylene, Vinylacetylene, and Diacetylene. J. Phys. Chem. 67, 1579-1581. https://doi.org/10.1021/j100802a004

IARC monographs on the evaluation of carcinogenic risks to humans [WWW Document], 2017. URL http://monographs.iarc.fr/ENG/Classification/index.php (accessed 4.16.17).

Krestinin, A.V., Kislov, M.B., Raevskii, A.V., Kolesova, O.I., Stesik, L.N., 2000. On the mechanism of soot particle formation. Kinet. Catal. 41, 90-98. https://doi.org/10.1007/BF02756146

Kuwana, K., Li, T., Saito, K., 2006. Gas-phase reactions during CVD synthesis of carbon nanotubes: Insights via numerical experiments. Chem. Eng. Sci. 61, 6718-6726. https://doi.org/10.1016/j.ces.2006.07.006

Lacroix, R., Fournet, R., Ziegler-Devin, I., Marquaire, P.-M., 2010. Kinetic modeling of surface reactions involved in CVI of pyrocarbon obtained by propane pyrolysis. Carbon 48, 132-144. https://doi.org/10.1016/j.carbon.2009.08.041

Li, C., Kuan, B., Lee, W.J., Burke, N., Patel, J., 2018. The non-catalytic partial oxidation of methane in a flow tube reactor using indirect induction heating - An experimental and kinetic modelling study. Chem. Eng. Sci. 187, 189-199. https://doi.org/10.1016/j.ces.2018.04.070

Matras, D., Villermaux, J., 1973. Un réacteur continu parfaitement agité par jets gazeux pour l'étude cinétique de réactions chimiques rapides. Chem. Eng. Sci. 28, 129-137. https://doi.org/10.1016/0009-2509(73)85093-6

Munson, M.S.B., Anderson, R.C., 1963. Vinylacetylene as an intermediate in the formation of acetylenic carbon. Carbon 1, 51-54. https://doi.org/10.1016/0008-6223(63)90009-5

Norinaga, K., Deutschmann, O., 2007. Detailed kinetic modeling of gas-phase reactions in the chemical vapor deposition of carbon from light hydrocarbons. Ind. Eng. Chem. Res. 46, $3547-3557$.

Norinaga, K., Deutschmann, O., Hüttinger, K.J., 2006. Analysis of gas phase compounds in chemical vapor deposition of carbon from light hydrocarbons. Carbon 44, 1790-1800. https://doi.org/10.1016/j.carbon.2005.12.050

Norinaga, K., Deutschmann, O., Saegusa, N., Hayashi, J., 2009. Analysis of pyrolysis products from light hydrocarbons and kinetic modeling for growth of polycyclic aromatic hydrocarbons with detailed chemistry. J. Anal. Appl. Pyrolysis 86, 148-160. https://doi.org/10.1016/j.jaap.2009.05.001 
Ogura, H., 1977. Pyrolysis of Acetylene behind Shock Waves. Bull. Chem. Soc. Jpn. 50, 1044-1050. https://doi.org/10.1246/bcsj.50.1044

Pease, R.N., 1929. The kinetics of the polymerization of acetylene. J. Am. Chem. Soc. 51, 3470-3475.

Richter, H., Howard, J.B., 2000. Formation of polycyclic aromatic hydrocarbons and their growth to soot-a review of chemical reaction pathways. Prog. Energy Combust. Sci. 26, 565-608.

Rokstad, O.A., Lindvaag, O.A., Holmen, A., 2014. Acetylene Pyrolysis in Tubular Reactor. Int. J. Chem. Kinet. 46, 104-115. https://doi.org/10.1002/kin.20830

Rota, R., Bonini, F., Servida, A., Morbidelli, M., Carrà, S., 1994. Analysis of detailed kinetic schemes for combustion processes: Application to a methane-ethane mixture. Chem. Eng. Sci., Chemical Reaction Engineering: Science \& Technology 49, 4211-4221. https://doi.org/10.1016/S0009-2509(05)80016-8

Sánchez, Nazly E., Callejas, A., Millera, Á., Bilbao, R., Alzueta, M.U., 2012. Polycyclic Aromatic Hydrocarbon $(\mathrm{PAH})$ and Soot Formation in the Pyrolysis of Acetylene and Ethylene: Effect of the Reaction Temperature. Energy Fuels 26, 4823-4829. https://doi.org/10.1021/ef300749q

Sánchez, N.E., Callejas, A., Millera, A., Bilbao, R., Alzueta, M.U., 2012. Formation of PAH and soot during acetylene pyrolysis at different gas residence times and reaction temperatures. Energy 43, 30-36. https://doi.org/10.1016/j.energy.2011.12.009

Sánchez, N.E., Callejas, A., Millera, A., Bilbao, R., Alzueta, M.U., 2010. Determination of Polycyclic Aromatic Hydrocarbons (PAH) Adsorbed on Soot Formed in Pyrolysis of Acetylene at Different Temperatures. Aaas10 Adv. Atmospheric Aerosol Symp. 22, 131-136. https://doi.org/10.3303/CET1022021

Sánchez, N.E., Callejas, A., Salafranca, J., Millera, Á., Bilbao, R., Alzueta, M.U., 2013a. Formation and characterization of polyaromatic hydrocarbons, in: Cleaner Combustion Developing Detailed Chemical Kinetic Models. pp. 283-302.

Sánchez, N.E., Millera, Á., Bilbao, R., Alzueta, M.U., 2013b. Polycyclic aromatic hydrocarbons (PAH), soot and light gases formed in the pyrolysis of acetylene at different temperatures: Effect of fuel concentration. J. Anal. Appl. Pyrolysis 103, 126-133. https://doi.org/10.1016/j.jaap.2012.10.027

Shukla, B., Koshi, M., 2012. A novel route for PAH growth in HACA based mechanisms. Combust. Flame 159, 3589-3596. https://doi.org/10.1016/j.combustflame.2012.08.007 
Shukla, B., Susa, A., Miyoshi, A., Koshi, M., 2008. Role of Phenyl Radicals in the Growth of Polycyclic Aromatic Hydrocarbons. J. Phys. Chem. A 112, 2362-2369. https://doi.org/10.1021/jp7098398

Shukla, B., Susa, A., Miyoshi, A., Koshi, M., 2007. In Situ Direct Sampling Mass Spectrometric Study on Formation of Polycyclic Aromatic Hydrocarbons in Toluene Pyrolysis. J. Phys. Chem. A 111, 8308-8324. https://doi.org/10.1021/jp071813d

Silcocks, C.G., 1957. The Kinetics of the Thermal Polymerization of Acetylene. Proc. R. Soc. Lond. Math. Phys. Eng. Sci. 242, 411-429. https://doi.org/10.1098/rspa.1957.0185

Stehling, F.C., Frazee, J.D., Anderson, R.C., 1961. Mechanisms of nucleation in carbon formation. Symp. Int. Combust., Eighth Symposium (International) on Combustion 8, 774784. https://doi.org/10.1016/S0082-0784(06)80572-2

Stehling, F.C., Frazee, J.D., Anderson, R.C., 1957. Carbon formation from acetylene. Symp. Int. Combust., Sixth Symposium (International) on Combustion 6, 247-254. https://doi.org/10.1016/S0082-0784(57)80035-6

Straif, K., Baan, R., Grosse, Y., Secretan, B., El Ghissassi, F., Cogliano, V., 2005. Carcinogenicity of polycyclic aromatic hydrocarbons. Lancet Oncol. 6, 931-932. https://doi.org/10.1016/S1470-2045(05)70458-7

Violi, A., D’Anna, A., D’Alessio, A., 1999. Modeling of particulate formation in combustion and pyrolysis. Chem. Eng. Sci. 54, 3433-3442. https://doi.org/10.1016/S00092509(98)00460-6

Wu, C.H., Singh, H.J., Kern, R.D., 1987. Pyrolysis of Acetylene Behind Reflected ShockWaves. Int. J. Chem. Kinet. 19, 975-996. https://doi.org/10.1002/kin.550191104

Xu, X.J., Pacey, P.D., 2005. Oligomerization and cyclization reactions of acetylene. Phys. Chem. Chem. Phys. 7, 326-333. https://doi.org/10.1039/b412585a

Yada, K., Watanabe, O., 2013. Reactive flow simulation of vacuum carburizing by acetylene gas. Comput. Fluids 79, 65-76. https://doi.org/10.1016/j.compfluid.2013.03.005

Yan, B., Xu, P., Jin, Y., Cheng, Y., 2012. Understanding coal/hydrocarbons pyrolysis in thermal plasma reactors by thermodynamic analysis. Chem. Eng. Sci. 84, 31-39. https://doi.org/10.1016/j.ces.2012.08.005 


$\begin{array}{llr}\text { Nomenclature } & \\ \mathrm{F} & \text { filter } & (-) \\ \mathrm{M} & \text { mass flow controllers } & (-) \\ \mathrm{P} & \text { pressure } & \mathrm{Pa} \\ \mathrm{T} & \text { temperature } & \mathrm{K}\end{array}$

PAHs

$\mathrm{B}[a] \mathrm{A} \quad$ Benzo $[a]$ anthracene (CAS: 56-55-3)

$\mathrm{B}[a] \mathrm{P} \quad$ Benzo $[a]$ pyrene (CAS: 50-32-8)

$\mathrm{B}[b] \mathrm{F} \quad$ Benzo[b]fluoranthene (CAS: 205-99-2)

$\mathrm{B}[$ ghi $] \mathrm{P} \quad$ Benzo[ghi $]$ perylene (CAS: 191-24-2)

$\mathrm{B}[k] \mathrm{F} \quad$ Benzo[k]fluoranthene (CAS: 207-08-9)

$\mathrm{DB}[a, h] \mathrm{A} \quad$ Dibenzo $[a, h]$ anthracene (CAS: 53-70-3)

$\mathrm{I}[1,2,3-c d] \mathrm{P} \quad$ Indeno[1,2,3-cd]pyrene (CAS: 193-39-5)

Acronyms

CVD chemical vapor deposition

EPA (United States) Environmental Protection Agency

GC gas chromatograph

HACA hydrogen abstraction $\mathrm{C}_{2} \mathrm{H}_{2}$ addition mechanism

IARC International Agency for Research on Cancer

MS mass spectrometry

PAH Polycyclic Aromatic Hydrocarbon

TCD thermal conductivity detector

FID flame ionization detector 